Check for updates

Cite this: Chem. Sci., 2018, 9, 119

Received 3rd July 2017

Accepted 10th November 2017

DOI: $10.1039 / \mathrm{c} 7 \mathrm{sc} 02925 \mathrm{j}$

rsc.li/chemical-science

\section{Enforcing Ising-like magnetic anisotropy via trigonal distortion in the design of a W(v)-Co(II) cyanide single-chain magnet +}

\author{
Yuan-Zhu Zhang, ${ }^{\text {ab }}$ Brian S. Dolinar, (D) ${ }^{a}$ Shihao Liu, ${ }^{b}$ Andrew J. Brown, ${ }^{a}$ \\ Xuan Zhang, (D) ${ }^{\text {a }}$ Zhao-Xi Wang ${ }^{a}$ and Kim R. Dunbar (iD *a
}

A new octacyanotungstate $(v)$ based single chain magnet $\left\{\left[(\mathrm{Tpm}) \mathrm{Co}(\mathrm{DMF}) \mathrm{W}(\mathrm{CN})_{8}\right]_{2}\left[\mathrm{Co}(\mathrm{DMF})_{4}\right] \cdot 2 \mathrm{DMF}\right\}_{n}$ $\left(1, T p m=1,1,1\right.$-trispyrazoylmethane), with an effective barrier of $39.7(3) \mathrm{cm}^{-1}$ is reported. The Ising-like magnetic anisotropy of the chain originates from the nearly parallel local orientations of the Co(॥) ions with the source of the uniaxial magnetic anisotropy being a trigonal distortion of the octahedral environment with the fac-tridentate capping Tpm ligand.

\section{Introduction}

Since the first experimental verification of Glauber dynamics ${ }^{1}$ for a cobalt(II)-nitronyl nitroxide radical chain complex in $2001,^{2}$ the phenomenon of slow relaxation in 1-D Ising paramagnets, known as single-chain magnets (SCMs), ${ }^{3}$ has received a great deal of attention in the field of molecular magnetism. ${ }^{4}$ The overall energy barrier $\left(\Delta_{\tau}\right)$ for reversing the direction of magnetization of an SCM is a sum of the correlation $\left(\Delta_{\xi}\right)$ and anisotropy $\left(\Delta_{\mathrm{A}}\right)$ energies. As such, SCMs have the potential to exhibit higher blocking temperatures than their zerodimensional counterpart, namely single-molecule magnets (SMMs) because of the additional correlation energy and the potential to optimize the magnetic coupling $(J)$ and zero field splitting $(D)$. For example, the introduction of bulky, rigid pyrene into the Co(II)-nitronyl nitroxide radical system led to stronger magnetic coupling, which in turn resulted in a SCM with a record blocking temperature of $14 \mathrm{~K}^{5}$

An increasing number of SCMs are being realized from the application of design principles involving the selection of specific bridging units in combination with polynuclear anisotropic metal complexes with ancillary blocking ligands. ${ }^{6}$ The use of polynuclear SMMs as building blocks for the construction of SCMs represents a promising strategy, but enforcing the proper alignment of the subunits to afford Ising-like anisotropy

\footnotetext{
${ }^{a}$ Department of Chemistry, Texas A \& M University, College Station, TX 77842, USA. E-mail: dunbar@chem.tamu.edu; Fax: +1 9798457177

${ }^{b}$ Department of Chemistry, Southern University of Science and Technology, Shenzhen, 518055, P. R. China

$\dagger$ This project was granted financial support from the Department of Energy (DE-FG02-02ER45999). Funds for the SQUID magnetometer were obtained from the National Science Foundation.

\$ Electronic supplementary information (ESI) available. CCDC 1508991. For ESI and crystallographic data in CIF or other electronic format see DOI: $10.1039 / \mathrm{c} 7 \mathrm{sc} 02925 \mathrm{j}$
}

is a challenge. ${ }^{7}$ In this respect, the use of mononuclear SMMs as building blocks is an excellent approach to SCM design, as a number of these molecules have been found to exhibit high energy barriers due to the presence of large uniaxial anisotropy stemming from spin-orbit coupling and specific geometries and they possess only one easy axis to control. ${ }^{8}$ The use of an efficient bridging ligand is of utmost importance in the design of SCMs. In this vein, cyanometallate complexes have received considerable attention because of the efficient exchange coupling through the cyanide bridge and the prospect for preparing homologous series of magnetic materials using a modular approach. ${ }^{9}$ Modifications of cyanometallate complexes are readily accomplished via installation of suitable capping ligands which allow for effective tuning of the ligand field, redox potentials, and electronic configurations of the metal centers. Such adjustments had led to the realization of new functional materials including $\mathrm{SMMs}^{\mathbf{1 0}} \mathrm{SCMs}^{\mathbf{1 1}}$ and photomagnets. ${ }^{12}$

In the field of cyanometallate molecular magnets, a common building block that has been widely studied is the octacyanotungstate(v) ion which, as a $5 \mathrm{~d}$ transition metal complex, ${ }^{13}$ exhibits an enhanced ability for magnetic coupling through bridging ligands due to its diffuse orbitals. The introduction of Mn(III) Schiff base units as a source of anisotropy into compounds of $\left[\mathrm{W}(\mathrm{CN})_{8}\right]^{3-}$ resulted in the realization of SCMs, ${ }^{\mathbf{1 4}}$ but there are few other examples of chain compounds that behave as SCMs. ${ }^{15}$ In 2003, Li et al. reported a 3,2-chain compound $\quad\left\{\left[\mathrm{Co}(\mathrm{DMF})_{4} \mathrm{~W}(\mathrm{CN})_{8}\right]_{2}\left[\mathrm{Co}(\mathrm{DMF})_{4}\right]\right\}_{n} \quad\left(\mathbf{1}^{*}\right)$, which exhibits long range magnetic ordering below $8 \mathrm{~K}$ with coexistence of spin-glass behaviour. ${ }^{16}$ Later, Sieklucka and co-workers as well as the Dunbar group worked on modifying the Co(II) sites with mer-tridentate planar ligands which resulted in the isolation of the chain compounds $\left(\left\{[\mathrm{Co}(\mathrm{iPr}-\mathrm{Pybox})(\mathrm{MeOH})]_{3}\left[\mathrm{~W}(\mathrm{CN})_{8}\right]_{2} \cdot 5\right.\right.$. $5 \mathrm{MeOH} \cdot 0.5 \mathrm{H}_{2} \mathrm{O}$ and $\left.\left[(\mathrm{tptz}) \mathrm{Co}\left(\mathrm{H}_{2} \mathrm{O}\right) \mathrm{W}(\mathrm{CN})_{8}\right]_{2}\left[\mathrm{Co}\left(\mathrm{H}_{2} \mathrm{O}\right)_{4}\right] \cdot 2 \mathrm{H}_{2} \mathrm{O}\right\}_{n}$ (iPr-Pybox = 2,2'-(2,6-pyridinediyl)bis(4-isopropyl-2-oxazoline); 
tptz $=$ 2,4,6-tris(2-pyridyl)-1,3,5-triazine). ${ }^{17}$ Both compounds exhibit the onset of frequency dependent out-of-phase signals in the AC susceptibility data at $\sim 2 \mathrm{~K}$ but these results do not conform to bona fide SCM behavior. Nevertheless the findings hint at the potential for tuning the magnetic behaviour of such systems by modifying the coordination environment of the Co centers with different capping ligands in order to increase the uniaxial magnetic anisotropy.

Recently, we discovered that axial trigonal distortion of the crystal field affords a huge uniaxial magnetic anisotropy with a $D$ value on the order of $-100 \mathrm{~cm}^{-1}$ for the mononuclear cobalt(II) SMM $\left[\mathrm{Co}(\mathrm{Tpm})_{2}\right]\left(\mathrm{BPh}_{4}\right)_{2} \quad(\mathrm{Tpm}=1,1,1$-trispyrazol methane). ${ }^{18}$ Taking a cue from this work and the preceding discussion, the premise behind the present work was to incorporate these highly anisotropic, trigonally distorted cobalt SMMs into cyanometallate-based chain structures in order to probe if enhanced SCM behavior could be engendered. Herein we report a chain compound with a 3,2-chain structural archetype, viz., $\left\{\left[(\mathrm{Tpm}) \mathrm{Co}(\mathrm{DMF}) \mathrm{W}(\mathrm{CN})_{8}\right]_{2}\left[\mathrm{Co}(\mathrm{DMF})_{4}\right]\right\}_{n} \cdot 2 n \mathrm{DMF}(\mathbf{1}) . \S$ The structure is a derivative of $\mathbf{1}^{*}$, where uniaxial anisotropy has been deliberately introduced in the form of trigonal antiprismatic cobalt ions capped by the fac-tridentate ligand Tpm. The magnetic studies indicate that 1 exhibits long range antiferromagnetic ordering below $3.4 \mathrm{~K}$ and single chain magnetic behavior with $\Delta_{\text {eff }}=39.7(3) \mathrm{cm}^{-1}$ an astonishing enhancement compared to the properties of $\mathbf{1}^{*}$.

\section{Experimental}

\section{Starting materials}

The ligand Tpm and $\left[(n-\mathrm{Bu})_{3} \mathrm{NH}\right]_{3}\left[\mathrm{~W}(\mathrm{CN})_{8}\right]$ were prepared according to literature procedures. ${ }^{21}$ All other chemicals and solvents were of commercially available reagent grade quality and used as received.

\section{Physical measurements}

Infrared (IR) spectra were measured as Nujol mulls placed between $\mathrm{KBr}$ plates on a Nicolet 740 FT-IR spectrophotometer. Direct current (dc) and alternating current (ac) susceptibility measurements were performed on a Quantum Design SQUID, Model MPMS XL-7 instrument. Single crystal X-ray data for $\mathbf{1}$ were collected on a Bruker APEX-II diffractometer equipped with CCD detectors at $110 \mathrm{~K}$.

\section{Synthesis of $\left\{\left[(\mathrm{Tpm}) \mathrm{Co}(\mathrm{DMF}) \mathrm{W}(\mathrm{CN})_{8}\right]_{2}\left[\mathrm{Co}(\mathrm{DMF})_{4}\right]\right\}_{n} \cdot 2 n \mathrm{DMF}$}

The reaction of $\mathrm{CoCl}_{2} \cdot 6 \mathrm{H}_{2} \mathrm{O}(36.0 \mathrm{mg}, 0.151 \mathrm{mmol})$ with $[(n$ $\left.\mathrm{Bu})_{3} \mathrm{NH}\right]_{3}\left[\mathrm{~W}(\mathrm{CN})_{8}\right] \cdot 4 \mathrm{H}_{2} \mathrm{O}(95.5 \mathrm{mg}, 0.100 \mathrm{mmol})$ in $2 \mathrm{~mL}$ of DMF afforded a green solution which was filtered and then layered with $1 \mathrm{~mL}$ of DMF as a buffer solution followed by $2 \mathrm{~mL}$ of $\mathrm{MeOH}$ containing Tpm (30.3 mg, $0.141 \mathrm{mmol})$. Thin red platelet crystals were collected after two weeks. Yield: $47.5 \mathrm{mg}, 48.0 \%$. Anal. calcd $\mathrm{C}_{60} \mathrm{H}_{76} \mathrm{Co}_{3} \mathrm{~N}_{36} \mathrm{O}_{8} \mathrm{~W}_{2}$ (F.W. $=1974.06 \mathrm{~g} \mathrm{~mol}^{-1}$ ): C, 36.51; H, 3.88; N, 25.54. Found: C, 36.36; H, 3.98; N, 25.73. IR (Nujol, $\mathrm{cm}^{-1}$ ): 3489 (w, br), 3135 (m), $2197(\mathrm{C} \equiv \mathrm{N}, \mathrm{w}), 2176$ $(\mathrm{C} \equiv \mathrm{N}, \mathrm{w})$ and $2138(\mathrm{C} \equiv \mathrm{N}, \mathrm{w}) \mathrm{cm}^{-1}, 1651$ (vs), $1519(\mathrm{~m}), 1497$ (m), 1456 (vs) 1404 (s), 1378 (vs), 1299 (m), 1288 (s), 1252 (s), 1221 (w), 1116 (m), 1093 (s), 1056 (s), 981 (m), 918 (w), 858 (s) (Fig. S1

\section{Results and discussion}

\section{Synthesis}

Compound 1 was synthesized by first reacting $\mathrm{CoCl}_{2} \cdot 6 \mathrm{H}_{2} \mathrm{O}$ in DMF with $\left[(n-\mathrm{Bu})_{3} \mathrm{NH}\right]_{3}\left[\mathrm{~W}(\mathrm{CN})_{8}\right] \cdot 4 \mathrm{H}_{2} \mathrm{O}$ to form a green solution. After layering the reaction mixture with a solution containing the supporting ligand Tpm, crystals of $\mathbf{1}$ formed over the course of two weeks. An IR spectrum of the compound shows features at $2197 \mathrm{~cm}^{-1}, 2176 \mathrm{~cm}^{-1}$, and $2138 \mathrm{~cm}^{-1}$, corresponding to the bridging and terminal cyanide stretches, respectively. Thermal gravimetric analysis (TGA) data revealed that the interstitial DMF solvent molecules (calcd 7.4\%) are gradually lost before compound 1 begins to decompose at $c a .180{ }^{\circ} \mathrm{C}$ (Fig. S2 $\$$ ). The phase purity of the product was verified by powder X-ray diffraction (PXRD) (Fig. S3 $\$$ ).

\section{Structural description}

Single crystal X-ray diffraction studies revealed that 1 crystallizes in the triclinic $P \overline{1}$ space group as a one-dimensional (1-D) array of $\left[(\mathrm{Tpm}) \mathrm{Co}(\mathrm{DMF}) \mathrm{W}(\mathrm{CN})_{8}\right]_{2}{ }^{2-}$ squares interconnected by $\left[\mathrm{Co}(\mathrm{DMF})_{4}\right]^{2+}$ moieties, best described as a 3,2-chain ${ }^{20}$ (Fig. 1). The asymmetric unit of the structure consists of one $\left[\mathrm{W}(\mathrm{CN})_{8}\right]^{3-}$ unit, and $1.5 \mathrm{Co}^{\mathrm{II}}$ centers bridged by cyanide. Each octacyanotungstate(v) unit (W1) is in a square antiprismatic geometry with an average W-C bond distance of 2.160(3) A. The W1 ion is linked to three cobalt centers via cyanide groups. The remaining five cyanide ligands are terminal. The Co1 ion is coordinated to one DMF molecule and adopts a pseudo-octahedral geometry that is distorted to a trigonal anitiprismatic environment due to the presence of the capping ligand Tpm with intra-ligand bite angles of $\mathrm{N}-\mathrm{Co}-\mathrm{N}$ in the range of $82.69(1)-84.23(1)^{\circ}$. The other cis $\mathrm{N}-\mathrm{Co}-\mathrm{N} / \mathrm{O}$ bond angles vary from $88.38(1)^{\circ}$ to $97.33(1)^{\circ}$. The $\mathrm{W} 1$ and $\mathrm{Co} 1$ atoms are bridged by cyanide to form a $\left[\mathrm{W}_{2} \mathrm{Co}_{2}\right]^{2-}$ square with a $\mathrm{N}-\mathrm{Co}-\mathrm{N}$ angle of $90.49(1)^{\circ}$.

The coordination geometries of Co1 in both 1 and $1^{*}$ were compared to an ideal octahedron using the SHAPE program. ${ }^{21}$ The coordination geometry of Co1 in $1^{*}$ is very close to an ideal octahedron $(\mathrm{CShM}=0.111)$ while the coordination geometry of Co1 in 1 exhibits substantially more distortion from an ideal

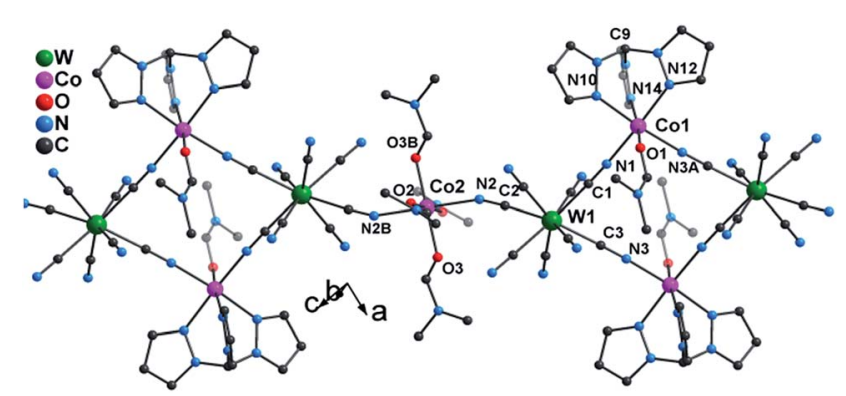

Fig. 1 X-ray structure of 1 . All hydrogen atoms and lattice solvents are eliminated for the sake of clarity. 
octahedron $(\mathrm{CShM}=0.297)$. This distortion is similar to that observed for $\left[\mathrm{Co}(\mathrm{Tpm})_{2}\right]\left(\mathrm{BPh}_{4}\right)_{2}(\mathrm{CShM}=0.450)$ and is consistent with the assignment of the geometry of Co1 in $\mathbf{1}$ as trigonal antiprismatic rather than octahedral.

The Co2 ion is located on an inversion center and adopts an elongated octahedral geometry with four DMF molecules in the equatorial plane $[\mathrm{Co}-\mathrm{O}=2.043(2)-2.055(2) \AA]$ and two $\left[\mathrm{W}^{\mathrm{V}}(\mathrm{CN})_{8}\right]^{3-}$ units coordinated in trans apical positions [Co$\left.\mathrm{N}_{\text {cyanide }}=2.139(2) \AA\right]$. The $\left[\mathrm{W}_{2} \mathrm{Co}_{2}\right]^{2-}$ squares are further linked via trans $-\left[\mathrm{Co}^{\mathrm{II}}(\mathrm{DMF})_{4}\right]^{2+}(\mathrm{Co} 2)$ fragments to form the overall 3,2chain structure. The cyanide linkages within the square deviate slightly from linearity with $\mathrm{W}^{\mathrm{V}}-\mathrm{C}-\mathrm{N}$ and $\mathrm{Co}^{\mathrm{II}}-\mathrm{N}-\mathrm{C}$ bond angles of $177.35(2)-178.42(2)^{\circ}$ and $172.67(2)-176.81(2)^{\circ}$, respectively. The cyanide linkages around $\mathrm{Co} 2$ are much more bent $[\mathrm{Co} 2-$ $\mathrm{N} 2-\mathrm{C} 2=155.9(5)^{\circ}$ and $\left.\mathrm{W} 1-\mathrm{C} 2-\mathrm{N} 2=175.68(2)^{\circ}\right]$, resulting in the nearest W-Co separation being 5.308(9) A within the chain. The chains are well isolated with the closest inter-chain metalmetal distances being 7.908(8), 8.478(7), and 9.814(1) A for Co $\cdots$ $\mathrm{Co}, \mathrm{Co} \cdots \mathrm{W}$ and $\mathrm{W} \cdots \mathrm{W}$, respectively; these values are comparable to those (8.21(2), 9.71(1), and 9.80(2) ^, respectively) found in the parent compound $\mathbf{1}^{*}$ (Fig. S4).

\section{Magnetic properties}

The variable temperature magnetic susceptibility data in an applied dc field of 1 kOe are plotted in Fig. 2 . At $300 \mathrm{~K}$, the $\chi_{\mathrm{m}} T$ value of $10.7 \mathrm{~cm}^{3} \mathrm{~mol}^{-1} \mathrm{~K}$ is much higher than the spin-only value $\left(6.375 \mathrm{~cm}^{3} \mathrm{~mol}^{-1} \mathrm{~K}\right)$ for three $\mathrm{Co}^{\mathrm{II}}\left(S_{\mathrm{Co}}=3 / 2, g=2.0\right)$ and two $\mathrm{W}^{\mathrm{V}}\left(S_{\mathrm{W}}=1 / 2, g=2.0\right)$ centers, in accord with significant spin-orbital coupling with $g_{\mathrm{Co}}=2.66$. Upon lowering the temperature, the $\chi_{\mathrm{m}} T$ value remains nearly constant until $\sim 50 \mathrm{~K}$ and then increases abruptly to a maximum of $68.4 \mathrm{~cm}^{3} \mathrm{~mol}^{-1} \mathrm{~K}$ at $3.5 \mathrm{~K}$, before decreasing to $51 \mathrm{~cm}^{3} \mathrm{~mol}^{-1} \mathrm{~K}$ at $2 \mathrm{~K}$. These results indicate overall ferromagnetic coupling between $\mathrm{W}(\mathrm{v})$ and $\mathrm{Co}(\mathrm{II})$ centers, consistent with other previously reported $\mathrm{W}^{\mathrm{V}}-\mathrm{Co}^{\mathrm{II}}$ complexes. ${ }^{22}$ No suitable model could be applied for further quantitative analysis of this system because of its complicated topology.

The isothermal field-dependent magnetization $(M v s . H)$ was measured at temperatures ranging from 1.8-7.0 K (Fig. S5ał).

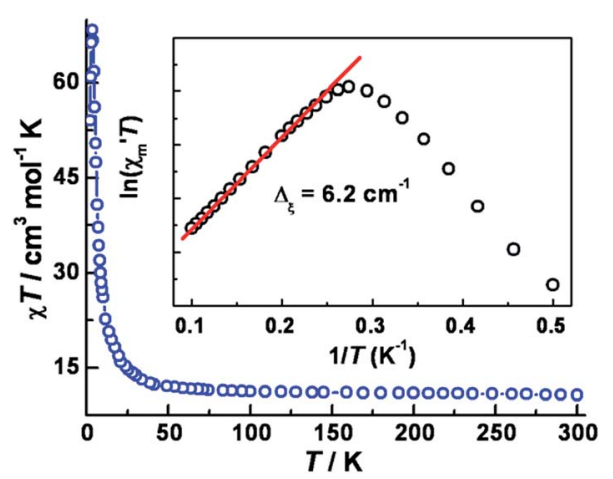

Fig. 2 Variable-temperature dc magnetic susceptibility data of 1 , collected in an applied field of $1 \mathrm{kOe}$. The inset: plot of $\ln \left(\chi_{\mathrm{m}}^{\prime} T\right)$ vs. 1/T (where $\chi_{m}^{\prime}$ is the molar component of the ac susceptibility at $1 \mathrm{~Hz}, H_{\mathrm{ac}}$ $=5$ Oe and $H_{\mathrm{dc}}=0$ ).

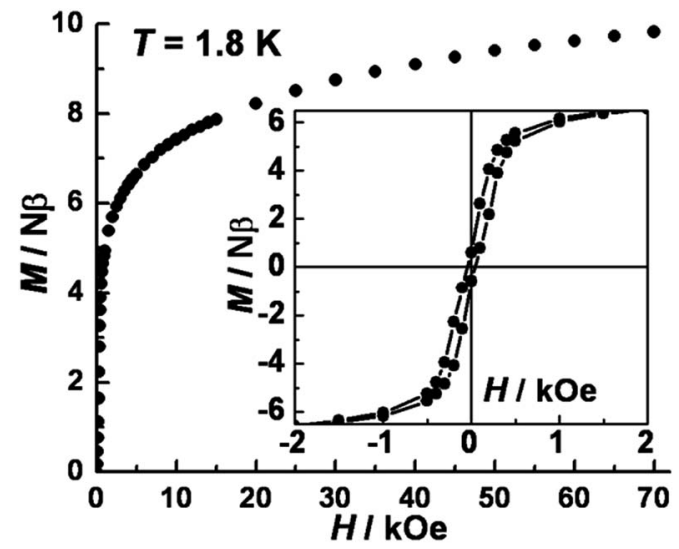

Fig. 3 Plot of isothermal field-dependent magnetization at $1.8 \mathrm{~K}$ for 1 . Inset: magnetic hysteresis loop with a sweeping rate of 60 Oe per min at $1.8 \mathrm{~K}$.

The magnetization at $1.8 \mathrm{~K}$ (Fig. 3) rapidly increases above zero field but does not saturate even at $7 \mathrm{~T}$. The value of $9.82 \mathrm{~N} \beta$ at 7 $\mathrm{T}$ is much lower than the expected saturation value of $\sim 14.0 \mathrm{~N} \beta$ for three $\mathrm{Co}^{\mathrm{II}}\left(S_{\mathrm{Co}}=3 / 2, g=2.66\right)$ and two $\mathrm{W}^{\mathrm{V}}\left(S_{\mathrm{W}}=1 / 2, g=2.0\right)$ ions, due to significant magnetic anisotropy as corroborated by the non-superposition of the $M v s$. $H / T$ plots at higher fields (Fig. S4b ). Plots of $\mathrm{d}(M) / \mathrm{d}(H) v s$. $H$ indicate a phase transition occurs from antiferromagnetic (AF) ordering to paramagnetic with a critical field of $300 \mathrm{Oe}$ at $1.8 \mathrm{~K}$ (Fig. S6\%). A narrow hysteresis loop at $1.8 \mathrm{~K}$ was observed with a coercive field of $\sim 40$ Oe and a remnant magnetization of $0.6 \mathrm{~N} \beta$. zero-field-cooled (ZFC) and field-cooled (FC) magnetization data collected under a field of 20 Oe showed a sharp peak at $3.4 \mathrm{~K}$ and irreversibility below $c a .2 .4 \mathrm{~K}$; the former feature suggests an AF ordering while the latter behavior represents the blocking temperature (Fig. S6 $\$$ ). Similar behavior has been noted for other cases of magnetic ordering in SCMs. ${ }^{23}$

In 1963, Glauber reported his prescient work describing an anisotropic Heisenberg or Ising-like one-dimensional system with the equation: $\chi_{\mathrm{m}} T / C_{\text {eff }}=\exp \left(\Delta_{\xi} / k_{\mathrm{B}} T\right)$, where $C_{\text {eff }}$ is the effective Curie constant, and $k_{\mathrm{B}}$ is the Boltzmann constant. From this relationship, $\chi_{\mathrm{m}} T$ is expected to increase exponentially with decreasing temperature under a zero applied dc field. Variable-temperature ac susceptibility data were collected in a zero applied dc field and an ac field of 5 Oe oscillating at $1 \mathrm{~Hz}$ (Fig. S7 $\$$. The resulting plot of $\ln \left(\chi_{\mathrm{m}}^{\prime} T\right)$ vs. $1 / T$ features a linear region in the temperature range $4.0-12 \mathrm{~K}$, yielding $\Delta_{\xi}=$ $6.2 \mathrm{~cm}^{-1}$ (inset of Fig. 2). Below $4.0 \mathrm{~K}, \ln \left(\chi_{\mathrm{m}}^{\prime} T\right)$ reaches a maximum and then undergoes a linear decrease with decreasing temperature.

To further probe the dynamics of the magnetization, ac magnetic susceptibility measurements were performed as a function of both temperature and frequency in a 5 Oe ac field and a zero dc field. As shown in Fig. 4a, variable-temperature ac susceptibilities for 1 display a strong frequency dependence of both in-phase $\left(\chi_{m}^{\prime}\right)$ and out-of-phase $\left(\chi^{\prime \prime}{ }_{m}\right)$ components. The shift of the peak temperature $\left(T_{\mathrm{p}}\right)$ of $\chi^{\prime}{ }_{\mathrm{m}}$, as evaluated by the Mydosh parameter $\varphi=\left(\Delta T_{\mathrm{p}} / T_{\mathrm{p}}\right) / \Delta(\log f) \approx 0.13$, is consistent with normal superparamagnetic behavior $(\varphi=0.1-0.3){ }^{24}$ 

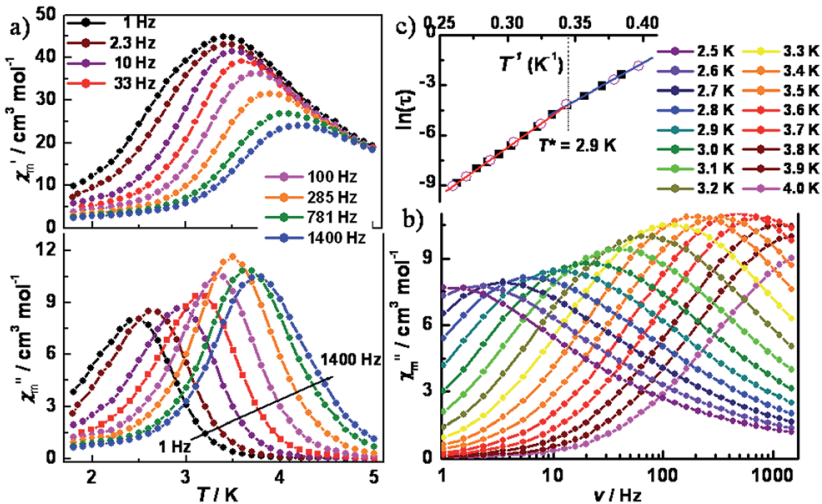

Fig. 4 Variable-temperature (a) and variable-frequency (b) in-phase $\left(\chi_{m}^{\prime}\right)$ and out-of-phase $\left(\chi_{m}^{\prime \prime}\right)$ ac magnetic susceptibility data for 1 , collected in a $5 \mathrm{Oe}$ ac field oscillating at temperatures of 1.8 to $5.0 \mathrm{~K}$ and frequencies of $1-1500 \mathrm{~Hz}$. (c) Arrhenius plot of relaxation times, as determined through variable-temperature $(O)$ and variable-frequency

) ac susceptibility measurements.

Variable-frequency ac susceptibilities collected in the range 2.5$4.0 \mathrm{~K}$ also show highly frequency dependent peaks (Fig. $4 \mathrm{~b}$ and S8 $\$$. The relaxation time, extracted from the peaks of $\chi_{m}^{\prime \prime}$ in Fig. 4, follows two thermally activated laws, corresponding to infinite-size and finite-size regimes, respectively, marked by the crossover temperature of $T^{*}=2.9 \mathrm{~K}$ (Fig. $4 \mathrm{c}$ ). A fitting based on the Arrhenius relationship $\tau=\tau_{0} \exp \left(\Delta / k_{\mathrm{B}} T\right)$ gave: $\Delta_{1}=$ $39.7(3) \mathrm{cm}^{-1}, \tau_{01}=3.4(5) \times 10^{-11} \mathrm{~s}$ for the infinite regime and $\Delta_{2}=31.8(2) \mathrm{cm}^{-1}, \tau_{02}=2.2(4) \times 10^{-9} \mathrm{~s}$ for the finite regime. Given the relationship between the energy barriers for a SCM system, $\Delta_{1}=2 \Delta_{\xi}+\Delta_{\mathrm{A}}$ and $\Delta_{2}=\Delta_{\xi}+\Delta_{\mathrm{A}}$, the anisotropy $\left(\Delta_{\mathrm{A}}\right)$ and correlation energy $\left(\Delta_{\xi}\right)$ were calculated to be 23.9 and $7.9 \mathrm{~cm}^{-1}$, respectively. The latter value is consistent with $6.2 \mathrm{~cm}^{-1}$ as estimated from the $\ln \left(\chi_{\mathrm{m}}^{\prime} T\right) v s .1 / T$ plot. The small correlation energy may be due to the weak magnetic coupling between the $\mathrm{W}(\mathrm{v})$ and $\mathrm{Co}(\mathrm{II})$ ions across the cyanide bridge, which was found to be $\sim 0.7 \mathrm{~cm}^{-1}$, according to the $2 J$ formalism of the exchange Hamiltonian..$^{22}$ Based on $\left|4 \Delta_{\mathrm{A}} / \Delta_{\xi}\right|$, the $|D / J|$ value was calculated to be 12.1, suggesting an Ising model for the current case. ColeCole plots (Fig. S9 $\$$ ) of $\chi_{m}^{\prime \prime} v s . \chi_{m}^{\prime}$ were fit to a generalized Debye model, ${ }^{25}$ giving $\alpha$ values ranging from 0.24 to 0.50 , indicative of a wide distribution of relaxation times, which could be caused by multiple relaxation processes, poly-dispersity of the chain length, magnetic interchain interactions, and/or random defects.

The decrease in the magnitude of the maximum intensity of $\chi^{\prime \prime}{ }_{m}$ upon lowering the temperature and frequencies is attributed to unaccounted for AF interchain interactions. To test this hypothesis, additional ac susceptibilities were measured under a dc field of 500 Oe, which minimizes the effect of antiferromagnetic interchain interactions (Fig. 5, S10 and S11). As shown in Fig. S11, $\$$ classical SCM behaviour is observed. The effective energy barrier for the infinite and finite regimes was estimated to be 38.3(2) and 25.1(7) $\mathrm{cm}^{-1}$, respectively (Fig. 5b). The difference between the two energy barriers is almost double that of $\Delta_{\xi}$, likely originating from the contribution of the applied dc field. The $\alpha$ values from fitting the Cole-Cole plot
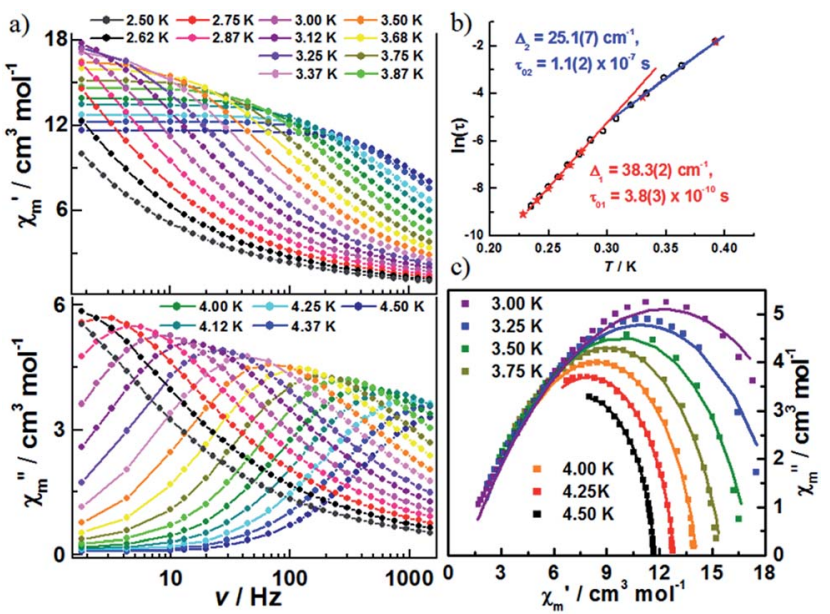

Fig. 5 (a) Variable-frequency in-phase $\left(\chi_{m}^{\prime}\right)$ and out-of-phase $\left(\chi_{m}^{\prime \prime}\right)$ ac magnetic susceptibility data for 1 , collected in a 500 Oe dc field and $5 \mathrm{Oe}$ ac field oscillating at temperatures of 2.5 to $4.5 \mathrm{~K}$ and frequencies of $1-1500 \mathrm{~Hz}$; (b) Arrhenius plot of relaxation times, as determined from variable-temperature $(\star)$ and variable-frequency $(O)$ ac susceptibility measurements; (c) selected Cole-Cole diagrams of 1 at 3.0-4.5 K; the solid lines are least-square fittings for a distribution of single relaxation processes with a generalized Debye model.

(Fig. 5c) based on a generalized Debye model were moderately reduced (in the range of $0.15-0.41$ ), which suggests that the interchain interactions do not entirely account for the wide range of relaxation in $\mathbf{1 .}$

The rapidly increasing number of mononuclear SMMs in the literature indicates the progress that is being made in predicting magneto-structural correlations. Spin-orbit coupling, the main source of magnetic anisotropy, can be tuned with intentional structural modifications to target a specific geometry or distortion. ${ }^{8 a}$ Although achieving such correlations still remains a complex issue for octahedral $\mathrm{Co}(\mathrm{II})$ systems, recent findings indicate that a majority of six-coordinate cobalt(II) compounds, such as those in an elongated octahedral geometry, exhibit easyplane anisotropy $(D>0){ }^{26}$ Very recently, both theory and experiment suggest that uniaxial magnetic anisotropy $(D<0)$ can be introduced and/or enhanced by increasing the axial trigonal distortion of the crystal field wherein the easy axis is coincident with the $C_{3}$ axis. In 2013, the Gao group corroborated this principle with their report of a mixed-valence $\left[\mathrm{Co}_{3}{ }^{\mathrm{III}} \mathrm{Co}^{\mathrm{II}}\right]$ cluster with a $\mathrm{Co}(\mathrm{II})$ ion in a slightly distorted triangular prismatic geometry that exhibits a large uniaxial magnetic anisotropy $\left(D_{\mathrm{Co}}\right.$ $\left.=-115 \mathrm{~cm}^{-1}\right) \cdot{ }^{27}$ In this vein, we recently demonstrated a successful way to realize very large negative $D$ values on the order of $-100 \mathrm{~cm}^{-1}$ by preparing trigonal antiprismatic mononuclear cobalt(II) SMMs $\left[\mathrm{Co}(\mathrm{Tpm})_{2}\right][\mathrm{X}]_{2}$, complexes. ${ }^{18}$

The SCM behaviour in $\mathbf{1}$ can be better understood by comparing the properties to the previously reported $1^{*}$ in terms of their respective structures (Table S1 $\$$ ). In $1^{*}$, both Co1 and Co2 centers adopt a slightly elongated octahedral geometry with a dihedral angle of $26.5^{\circ}$ between their equatorial planes (easyplane); ${ }^{16}$ whereas in $\mathbf{1}$, while Co2 still adopts an elongated octahedral geometry (easy-plane anisotropy), the Co1 center is now trigonally distorted by virtue of the presence of the Tpm 


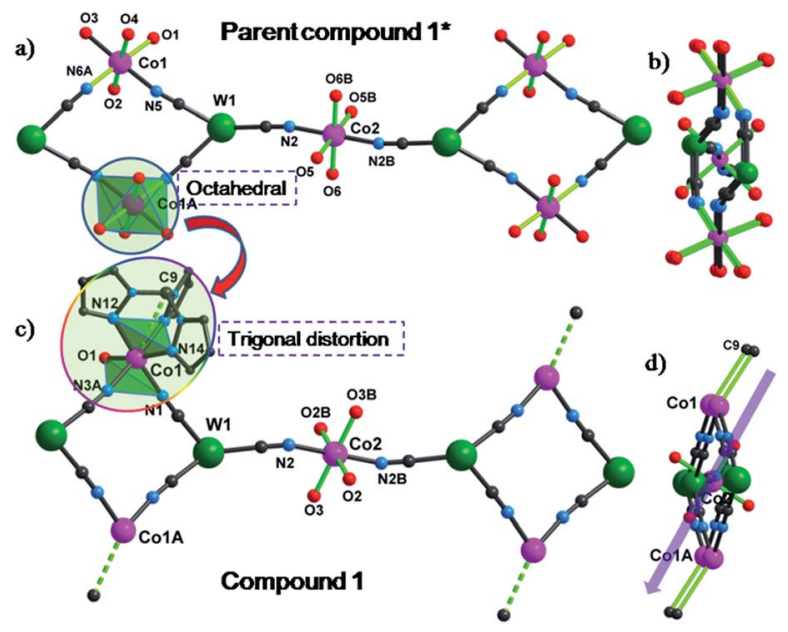

Fig. 6 Truncated structure of the parent compound $1^{*}$ (a) along and (b) through the chain direction; truncated structure of compound 1 (c) along and (d) through the chain direction. The green bonds represent easy axes of Co ions.

capping ligand which engenders uniaxial magnetic anisotropy along the $C_{3}$ axis (Co1-C9). This very important distinction leads to differences in magnetic behaviour that can be rationalized by considering the easy axes of each compound, indicated by the green lines in Fig. 6 . Compound $1^{*}$ which is not an SCM does not have alignment of the easy plane anisotropy axes and is reported to exhibit glassy magnetic behavior and long range magnetic ordering. In the case of 1, the Co1-C9 bond is nearly parallel to the $\mathrm{Co} 2-\mathrm{O} 3$ bond (one preferred orientation within the easy plane) with a small angle of $2.7^{\circ}$; therefore, the projection along the Co1-C9 direction of the anisotropy tensors results in Ising-like magnetic anisotropy with $g_{z}>g_{x} \neq g_{y}$, consistent with the above estimation $(|D / J|>4 / 3)$.

\section{Concluding remarks}

This work highlights the advantage of incorporating the principles of mononuclear SMMs into the design of SCMs. The trigonal symmetry that is essential to the SMM properties of $\left[\mathrm{Co}(\mathrm{Tpm})_{2}\right]\left(\mathrm{BPh}_{4}\right)_{2}$ served as a guiding principle in the design of 1. The use of Tpm in the synthesis of $\mathbf{1}$ engendered coalignment of uniaxial magnetic anisotropies along the $C_{3}$ axes of the $\mathrm{Co}^{\mathrm{II}}$ moieties, resulting in good SCM behaviour, whereas its non-trigonal counterpart, $\mathbf{1}^{*}$, is not an SCM. Future efforts to incorporate this trigonal distortion into SCMs with other cyanometallates as linkers will be explored.

\section{Conflicts of interest}

There are no conflicts to declare.

\section{Acknowledgements}

The authors gratefully funding from the National Science Foundation (CHE-1310574) and the Robert A. Welch Foundation (A-1449).

\section{Notes and references}

§ Crystal data for $\mathbf{1}$ (CCDC 1508991): $\mathrm{C}_{60} \mathrm{H}_{76} \mathrm{Co}_{3} \mathrm{~N}_{36} \mathrm{O}_{8} \mathrm{~W}_{2}$, F.W. $=1974.06$, triclinic, space group $P \overline{1}, a=11.910(3), b=12.221(3), c=15.587(4) \AA, \alpha=69.947(3)^{\circ}, \beta=$ $81.802(3)^{\circ}, \gamma=66.513(3)^{\circ}, V=1954.5(9) \AA^{3}, T=110(2) \mathrm{K}, Z=1, \mu=3.629 \mathrm{~mm}^{-1}$, $\rho_{\text {calcd }}=1.677 \mathrm{Mg} \mathrm{m}^{-3}, R_{1}=0.0394, \mathrm{w}_{2}=0.0793$.

1 R. J. Glauber, J. Math. Phys., 1963, 4, 294-\&.

2 A. Caneschi, D. Gatteschi, N. Lalioti, C. Sangregorio, R. Sessoli, G. Venturi, A. Vindigni, A. Rettori, M. G. Pini and M. A. Novak, Angew. Chem., Int. Ed., 2001, 40, 1760-1763.

3 R. Clérac, H. Miyasaka, M. Yamashita and C. Coulon, J. Am. Chem. Soc., 2002, 124, 12837-12844.

4 (a) D. Gatteschi and A. Vindigni, Single-Chain Magnets, Springer-Verlag, Berlin Heidelberg, 2014, pp. 191-220; (b) C. Coulon, V. Pianet, M. Urdampilleta and R. Clérac, Molecular Nanomagnets, Springer-Verlag, Berlin Heidelberg, 2015, pp. 143-184.

5 M. G. F. Vaz, R. A. A. Cassaro, H. Akpinar, J. A. Schlueter, P. M. Lahti and M. A. Novak, Chem.-Eur. J., 2014, 20, 54605467.

6 (a) H. Miyasaka, M. Julve, M. Yamashita and R. Clerac, Inorg. Chem., 2009, 48, 3420-3437; (b) H.-L. Sun, Z.-M. Wang and S. Gao, Coord. Chem. Rev., 2010, 254, 1081-1100; (c) W.-X. Zhang, R. Ishikawa, B. Breedlove and M. Yamashita, RSC Adv., 2013, 3, 3772-3798.

7 I.-R. Jeon and R. Clérac, Dalton Trans., 2012, 41, 9569-9586. 8 (a) S. Gómez-Coca, E. Cremades, N. Aliaga-Alcalde and E. Ruiz, J. Am. Chem. Soc., 2013, 135, 7010-7018; (b) M. Atanasov, D. Aravena, E. Suturina, E. Bill, D. Maganas and F. Neese, Coord. Chem. Rev., 2015, 289-290, 177-214 and references therein (c) S. Gómez-Coca, D. Aravena, R. Morales and E. Ruiz, Coord. Chem. Rev., 2015, 289-290, 379-392 and references therein.

9 K. S. Pedersen, J. Bendix and R. Clérac, Chem. Commun., 2014, 50, 4396-4415.

10 (a) D. E. Freedman, D. M. Jenkins, A. T. Iavarone and J. R. Long, J. Am. Chem. Soc., 2008, 130, 2884-2885; (b) Y.-Z. Zhang, B.-W. Wang, O. Sato and S. Gao, Chem. Commun., 2010, 46, 6959-6961; (c) K. Qian, X.-C. Huang, C. Zhou, X.-Z. You, X.-Y. Wang and K. R. Dunbar, J. Am. Chem. Soc., 2013, 135, 13302-13305.

11 (a) R. Lescouëzec, J. Vaissermann, C. Ruiz-Pérez, F. Lloret, R. Carrasco, M. Julve, M. Verdaguer, Y. Dromzee, D. Gatteschi and W. Wernsdorfer, Angew. Chem., Int. Ed., 2003, 42, 1483-1486; (b) S. Wang, J.-L. Zuo, S. Gao, Y. Song, H.-C. Zhou, Y.-Z. Zhang and X.-Z. You, J. Am. Chem. Soc., 2004, 126, 8900-8901; (c) M. Ferbinteanu, H. Miyasaka, W. Wernsdorfer, K. Nakata, K.-i. Sugiura, M. Yamashita, C. Coulon and R. Clérac, J. Am. Chem. Soc., 2005, 127, 3090-3099; (d) T. D. Harris, M. V. Bennett, R. Clérac and J. R. Long, J. Am. Chem. Soc., 2010, 132, 3980-3988; (e) R. Ababei, C. Pichon, O. Roubeau, Y.-G. Li, N. Bréfuel, L. Buisson, P. Guionneau, C. Mathonière and R. Clérac, J. Am. Chem. Soc., 2013, 135, 14840-14853. 
12 D. Aguilà, Y. Prado, E. S. Koumousi, C. Mathonière and R. Clérac, Chem. Soc. Rev., 2016, 45, 203-224 and references therein.

13 B. Nowicka, T. Korzeniak, O. Stefanczyk, D. Pinkowicz, S. Chorazy, R. Podgajny and B. Sieklucka, Coord. Chem. Rev., 2012, 256, 1946-1971.

14 (a) S. Dhers, H. L. C. Feltham, R. Clérac and S. Brooker, Inorg. Chem., 2013, 52, 13685-13691; (b) J. Lee, K. Lim, J. Yoon, D. Ryu, B. Koo, E. Koh and C. Hong, Sci. China: Chem., 2012, 55, 1012-1017; (c) T. S. Venkatakrishnan, S. Sahoo, N. Bréfuel, C. Duhayon, C. Paulsen, A.-L. Barra, S. Ramasesha and J.-P. Sutter, J. Am. Chem. Soc., 2010, 132, 6047-6056; (d) D. Visinescu, A. M. Madalan, M. Andruh, C. Duhayon, J.-P. Sutter, L. Ungur, W. Van den Heuvel and L. F. Chibotaru, Chem.-Eur. J., 2009, 15, 11808-11814; (e) S. W. Choi, D. W. Ryu, J. W. Lee, J. H. Yoon, H. C. Kim, H. Lee, B. K. Cho and C. S. Hong, Inorg. Chem., 2009, 48, 9066-9068; (f) S. W. Choi, H. Y. Kwak, J. H. Yoon, H. C. Kim, E. K. Koh and C. S. Hong, Inorg. Chem., 2008, 47, 10214-10216.

15 R.-M. Wei, F. Cao, J. Li, L. Yang, Y. Han, X.-L. Zhang, Z. Zhang, X.-Y. Wang and Y. Song, Sci. Rep., 2016, 6, 24372.

16 D.-F. Li, L.-M. Zheng, Y.-Z. Zhang, J. Huang, S. Gao and W.-X. Tang, Inorg. Chem., 2003, 42, 6123-6129.

17 (a) S. Chorazy, K. Nakabayashi, K. Imoto, J. Mlynarski, B. Sieklucka and S.-i. Ohkoshi, J. Am. Chem. Soc., 2012, 134, 16151-16154; (b) H.-H. Zhao, A. J. Brown, A. V. Prosvirin and K. R. Dunbar, Polyhedron, 2013, 64, 321-327.

18 Y.-Z. Zhang, S. Gómez-Coca, A. J. Brown, M. R. Saber, X. Zhang and K. R. Dunbar, Chem. Sci., 2016, 7, 6519-6527. 19 (a) D. L. Reger, T. C. Grattan, K. J. Brown, C. A. Little, J. J. S. Lamba, A. L. Rheingold and R. D. Sommer, J. Organomet. Chem., 2000, 607, 120-128; (b) L. D. C. Bok,
J. G. Leipoldt and S. S. Basson, Z. Anorg. Allg. Chem., 1975, 415, 81-83.

20 J. Černák, M. Orendáč, I. Potočňák, J. Chomič, A. Orendáčova, J. Skoršepa and A. Feher, Coord. Chem. Rev., 2002, 224, 51-66.

21 (a) S. Alvarez, P. Alemany, D. Casanova, J. Cirera, M. Lunell and D. Avnir, Coord. Chem. Rev., 2005, 249, 1693-1708; (b) M. Lunell, D. Casanova, J. Cirera, P. Alemany and S. Alarez, SHAPE, 2013.

22 J. Wang, Y.-L. Xu, H.-B. Zhou, H.-S. Wang, X.-J. Song, Y. Song and X.-Z. You, Dalton Trans., 2010, 39, 3489-3494.

23 (a) C. Coulon, R. Clérac, W. Wernsdorfer, T. Colin and H. Miyasaka, Phys. Rev. Lett., 2009, 102, 167204; (b) I. Bhowmick, E. A. Hillard, P. Dechambenoit, C. Coulon, T. D. Harris and R. R. Clérac, Chem. Commun., 2012, 48, 9717-9719; (c) H. Miyasaka, K. Takayama, A. Saitoh, S. Furukawa, M. Yamashita and R. Clérac, Chem.-Eur. J., 2010, 16, 3656-3662; (d) D. Shao, S.-L. Zhang, X.-H. Zhao and X.-Y. Wang, Chem. Commun., 2015, 51, 4360-4363; (e) Y.-Z. Zhang, H.-H. Zhao, E. Funck and K. R. Dunbar, Angew. Chem., Int. Ed., 2015, 54, 5583-5587.

24 J. A. Mydosh, Spin Glasses: An Experimental Introduction, Taylor and Francis, London, 1993.

25 S. M. J. Aubin, Z. Sun, L. Pardi, J. Krzystek, K. Folting, L.-C. Brunel, A. L. Rheingold, G. Christou and D. N. Hendrickson, Inorg. Chem., 1999, 38, 5329-5340.

26 (a) A. Bencini, C. Benelli, D. Gatteschi and C. Zanchini, Inorg. Chem., 1980, 19, 1301-1304; (b) S. Karasawa, K. Nakano, J. Tanokashira, N. Yamamoto, T. Yoshizaki and N. Koga, Dalton Trans., 2012, 41, 13656-13667.

27 Y.-Y. Zhu, C. Cui, Y.-Q. Zhang, J.-H. Jia, X. Guo, C. Gao, K. Qian, S.-D. Jiang, B.-W. Wang, Z.-M. Wang and S. Gao, Chem. Sci., 2013, 4, 1802-1806. 